\title{
Operational Skill and TNA (Training Needs Analysis) for Generation Power Plant
}

\author{
Aouda Arfoa ${ }^{1}$, Qais Alsafasfeh ${ }^{1}$, Omar Alsaraereh ${ }^{2}$ and Jaber Alrawahi ${ }^{3}$ \\ 1. Power and Mechatronics Engineering Department, Tafila Technical University, Tafila 66110, Jordan \\ 2. Electrical Engineering Department, Hashemite University, Zarqa 13133, Jordan \\ 3. Wadi Al Jizzi Power Co., Sohar 322, Oman
}

Received: May 26, 2015 / Accepted: June 19, 2015 / Published: August 31, 2015.

\begin{abstract}
Training needs analysis is the preliminary step in a cyclical process which adds to the overall training and progress strategy of staff in a generation power plant or a professional group, questionnaires were distributed among WAJPCO (Wadi Al Jizzi Power Company) staff and their responses were used to conduct a training need and gap analyses with a view to identify the operational skill and the training needs of the generation power plant, the time and travel commitment the industry is willing to invest in employee training, and an understanding of what skills are considered specific to lumber manufacturing and what can be combined with the needs of other industries and taught locally.
\end{abstract}

Key words: Training needs analysis, power plant, operational skill.

\section{Introduction}

For a learning generation power plant to grow and develop, its staff must have the necessary operational skills and knowledge to deliver the services required, both now and in the future. To ensure that workforce stays fit for purpose and suitable for repetition, a generation power plant must have an effective training and progress strategy that addresses any performance gaps. Many researchers started working with TNA (training needs analysis) concept with many services like nursing [1], business [2], industry [3] and general education [4], also in Ref. [5], a case study and importance performance analysis are adopted to identify competency gaps. Based on the managerial competency framework, the importance of competency is determined using the Fuzzy Delphi, and the performance is estimated via 360 degree feedback, moreover the TNA is very helpful for the academic purpose at university level in Ref. [6], the outcomes of

Corresponding author: Qais Alsafasfeh, Ph.D., research fields: power system, renewable energy and nonlinear systems. E-mail: qsafasfeh@ttu.edu.jo, qshashim@yahoo.com. this study will be crucial to guide UiTM's (Universiti Teknologi MARA's) administration towards the direction of achieving a sustainable high quality academic staff development environment. In Ref. [7], TNA was conducted to enhance the operational skill of the manufacturer operators a three-step method is presented to solve the problem. The method includes key position analysis, key motion cells analysis and key skill cells analysis. Goldstein model, competency model and gap analysis model are introduced as methods to evaluate training needs process, and the practical process about training needs analysis is illustrated in detail, task competency analysis and personnel analysis process was presented in Ref. [8]. This study was aimed at enabling the ET (expert team) gain an indepth understanding of the required fast track capacity building requirements. The situational analysis aimed at giving the ET a quick synopsis of the base line performance in the areas of gas turbine power generation: major components design and construction; gas turbine support systems and major maintenance; operation of gas turbines; control \& protection systems 
and power plant controls.

The TNA was aimed at identifying the core training needs in the above areas as well as identification of any essential complimentary skill requirements such as basic IT and management. The whole exercise was aimed at gathering adequate material that would be useful in the designing of the training modules and the capacity building programme as a whole

The specific objectives of training needs assessment were to:

- get baseline information in the areas of gas turbine power generation: major components design and construction; gas turbine support systems and major maintenance; operation of gas turbines; control \& protection systems and power plant controls;

- identify core needs in the areas of gas turbine power generation: major components design and construction; gas turbine support systems and major maintenance; operation of gas turbines; control \& protection systems and power plant controls. As well as any essential complimentary skills such as IT and management;

- assistance and resources needed. What additional resources are needed to expand capacity?

- preferences regarding training format, length, and travel distance. How should trainings be delivered and where should they be held?

\section{Methodology}

The study area focused on WAJPCO (Wadi Al Jizzi Power Company), the study start with maintenance department, operation department, planning and procurements and stores department, visits were carried over a period of one week between December 4th-9th, 2014, the methods used to gather critical baseline information to assess the training needs and opportunities of power plant professionals throughout the state. In order to obtain this necessary information, the project team developed a comprehensive set of research questions that informed the creation of two surveys: training needs assessment survey, which targeted power plant professionals; indications for the needs of training, which targeted training courses. Both surveys were carried out as part of a larger effort to develop a comprehensive training plan for Wadi Al Jizzi Power Company, which is due to be released in late December, 2013. More detailed descriptions of the methodology used for each survey is described below. survey containing 65 questions (appendix A and B) was developed by the Petra training group to collect data from various professional groups in Wadi Al Jizzi Power Company in order to determine their familiarity with statewide training needs in power company. Interviews were held with key informants, members Wadi Al Jizzi Power Company and other leaders, staff of maintenance department, operation department, planning and procurements and stores. Focus group discussions were also held with key staff.

The number of responders for each question varies because responses to certain questions throughout the survey routed the responder to a specific set of questions (referred to as branching) and because some responders declined to answer all questions they were asked.

The ET visited the Wadi Al Jizzi Power Company, a simple indications for the needs of training questionnaire was developed and administered to about $70 \%$ of the total staff per utility (appendix A and B). The questionnaire was designed in such a way that basic information could be acquired on the skills, qualification, abilities and training needs of the individual.

Interviews were held with key informants, members Wadi Al Jizzi Power Company and other leaders, staff of maintenance department, operation department, planning and procurements and stores. Focus group discussions were also held with key staff available records, databases and documents were reviewed and an assessment made of the processes and management systems in place. The sampling of data reviewed was done randomly but covered information in place over a period of at least two years where applicable. Soft 
copies of reports were obtained where possible.

\section{Results and Analysis}

A questionnaire was used to provide the training needs perception of the staff. The questionnaire was administered by the ET by direct interview and group conference. This needs assessment report is the first reporting of the findings of the needs assessment survey and therefore the full findings of that survey are contained herein. The questionnaire also focused on major areas of training that were pre-determined. The answers provided by the staff give their own perception of their training needs. These are summarized in Figs. 1-7.

The expert team carried out field visits to assess the on-ground condition of operations and assess the areas which were in need for plant personnel to be trained. The field visits targeted maintenance department, operation department, planning and procurements and stores. A check list provided baseline information

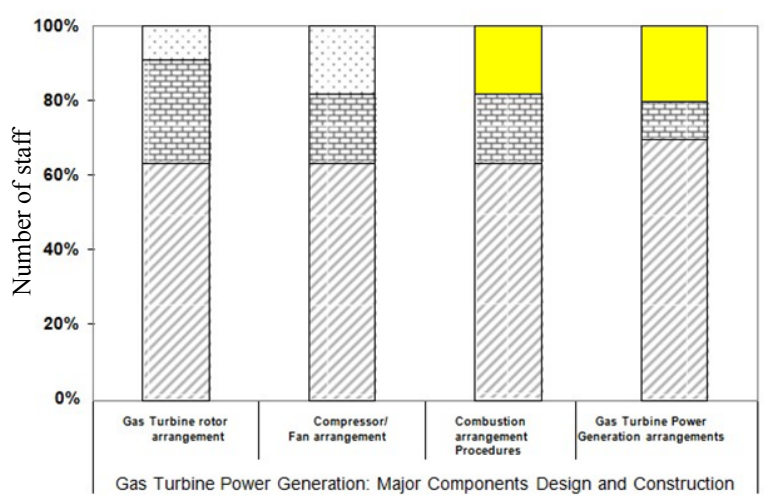

Fig. 1 Staff training aspirations in gas turbine power generation: major components design and construction.

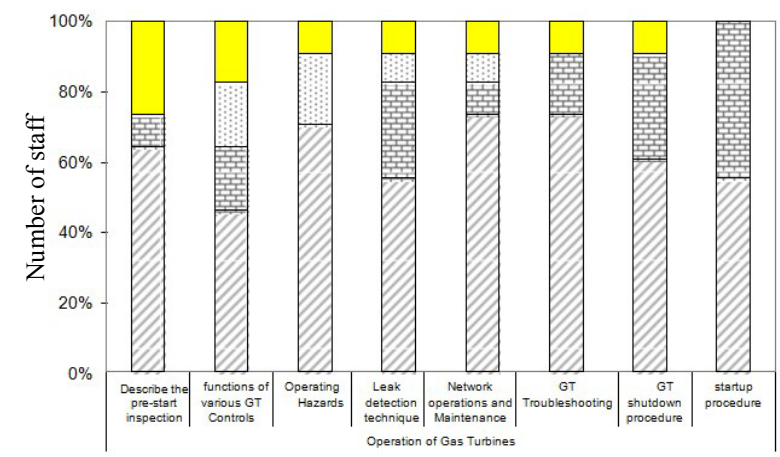

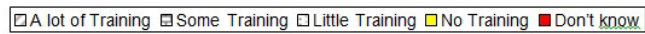

Fig. 2 Staff training aspirations in operation of gas turbine.

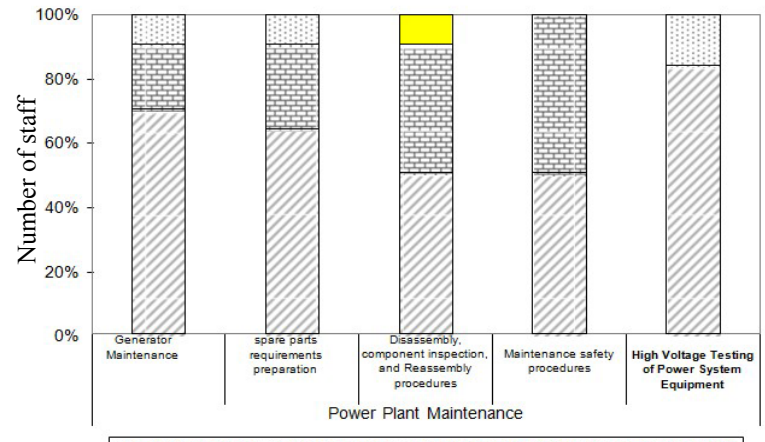

(a)

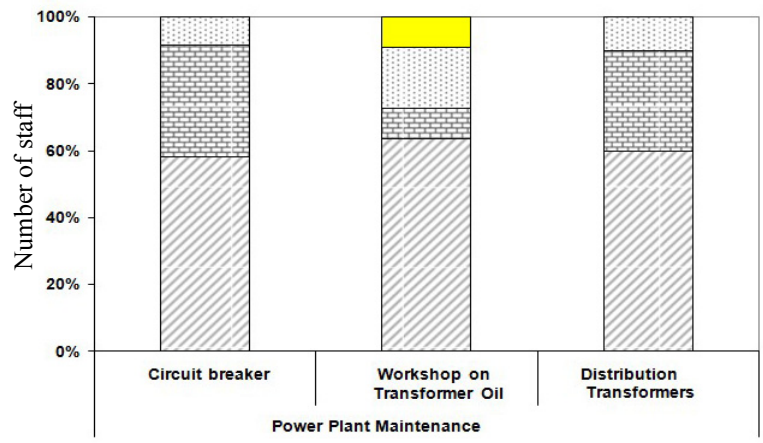

(b)

Fig. 3 Staff training aspirations in power plant maintenance.

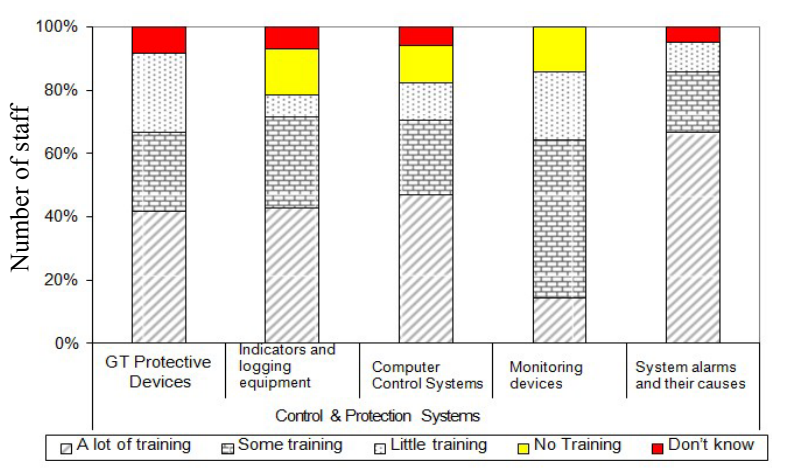

Fig. 4 Staff training aspirations in control \& protection systems.

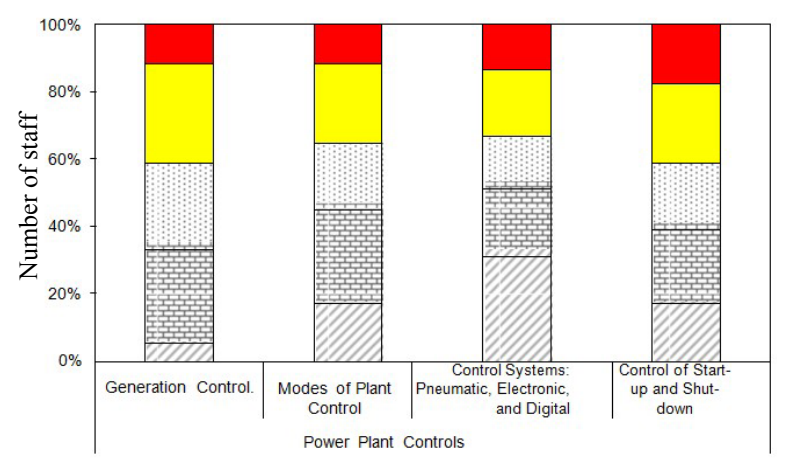

Fig. 5 Staff training aspirations in power plant controls. 


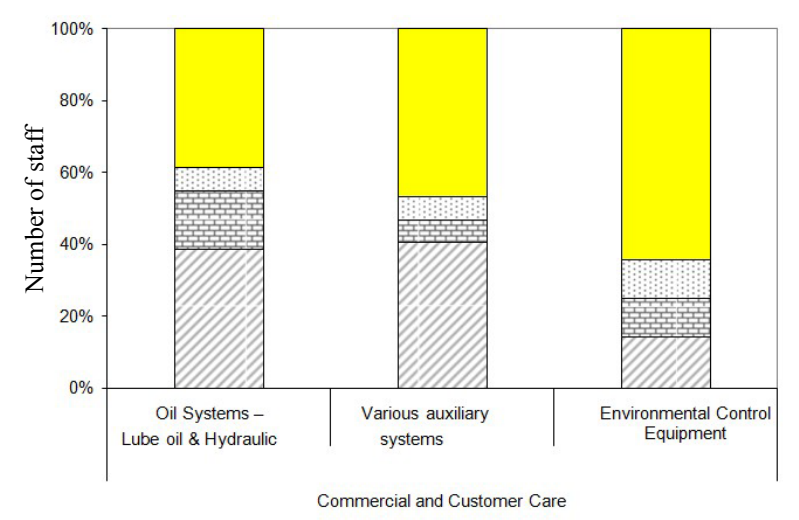

Fig. 6 Staff training aspirations in maintenance.

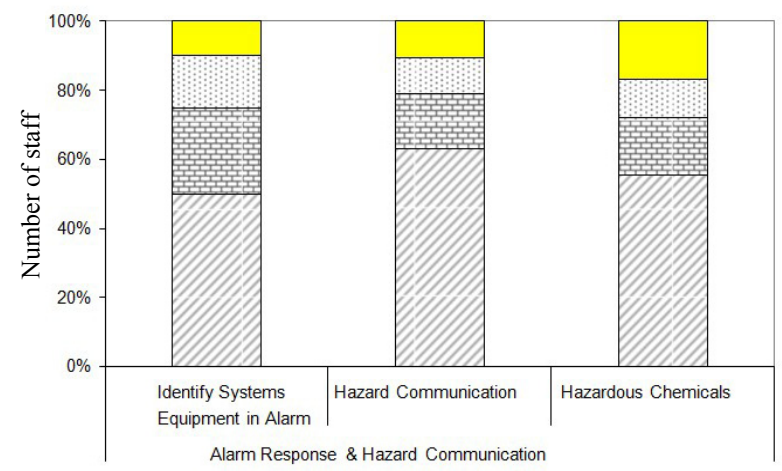

Fig. 7 Staff training aspirations in alarm response \& hazard communication.

further enhanced by focused group discussions and interviews. The major findings are described below during the survey, filling the questionnaires and interviews with members of staff (with different ranks) we noticed the following:

- There is a huge gap between the main supervisor and the team working under his supervision. This was obvious in many departments and causing a very weak relationship between the supervisor and his team which consequently lead to lack of trust and losing the soul of teamwork;

- Most of the times employers talk about training and focusing on practical training;

- During filling the questionnaires, we have noted that, there is a sever weakness in speaking and writing English language. It is very important to concentrate on this issue since the staff deal with English manuals and use standard English expressions and training courses for any new equipment usually lectured in
English;

- Responders have serious concerns about a number issues, topping the list is cost of maintenance and operations/maintenance. Developing regionally specific case studies could help address some of these concerns;

- The defect report covers the period from December 18， 2010 to November 20, 2013 (approximately 3 years) with total number of 1,060 defects. Around 413 defects have been solved by replacing new part. The replaced parts included the following Table 1 .

It can be noted that, the aforementioned parts include some traditional consumables such as fuses, gaskets, belts and isolators. Other major parts included thermocouples, motors, radiators, pumps, tap changers, compressors and torque convertors need rigorous investigation to check the main factors behind repetitive replacing of these parts and proper staff skills for examining and servicing.

Other major findings in Wadi Al-Jizzi Power Station are water leak and oil leak in different locations. Water leak was mainly concentrated and monotonous in the following locations.

Main cooling water pump and aux pump, diesel engine cooler system, Tower 1 stage 5 of radiators, cooling radiator under fans (1-6), VTR1 body joint gasket, cooling water radiator, support leg GT6, side, atomizing air cooler, battery cells, heavy water leak underground from hydrant line near GTS (north side) also oil leak was concentrated and monotonous as well in the following locations.

Diesel engine turbo charger, diesel engine cylinder head cover gasket, accessory gearbox in many parts

Table 1 list of replaced parts.

\begin{tabular}{llll}
\hline Thermocouples & $\begin{array}{l}\text { Pump } \\
\text { contactor }\end{array}$ & Motor & Fans \\
\hline Gasket & Fuses & Isolator & Tap changer \\
Fuel nozzle & Air cooler & Radiator core & belts \\
Air filters & Motor pump & Carbon brushes \\
Flame detectors & Injectors & Torque convertors \\
Switches & Compressors & & \\
\hline
\end{tabular}


such as lube oil pump side, drain line pipe, turbine cover and load gearbox (upper case), lube oil cooler 2, distillate of base filter (heavy leak), heat exchanger, HYD (hydraulic filter division) filter cover, exciter bearing, $11 \mathrm{kV}$ side cable box, starting motor, booster air compressor mechanical seal oil, IGV (inlet guide vane) solenoid valve, LO (radiative cooling) cooler east side, transformer gasket and generator bearing.

The survey results show important key findings, as well as gaps that will need to be addressed in the next phase of the project team's work. Among the key findings and gaps are the following sections.

\subsection{Gas Turbine Power Generation: Major} Components Design and Construction

The questionnaire reflected the following facts on the subject of gas turbine power generation:

- gas turbine rotor arrangement: $90 \%$ of the staff needs a lot of training in this aspect and the rest needs slight training;

- compressor/fan arrangement: $80 \%$ of the staff needs a lot of training in this aspect and the rest needs slight training;

- combustion arrangement procedures: $80 \%$ of the staff needs a lot of training in this aspect and the rest does not need any training;

- gas turbine power generation arrangements: around $76 \%$ of the staff needs a lot of training and the rest does not need any training.

Recommendations: The ET recommends an extensive training in all aspects of gas turbine power generation since the questionnaire revealed that more than $80 \%$ of the staff requires that.

\subsection{Operation of Gas Turbines}

The questionnaire reflected the following facts on the subject of operation of gas turbines:

- describe the pre-start inspection: $75 \%$ of the staff needs a lot of training in this aspect and the rest does not need any training;

- functions of various GT controls: around $62 \%$ of the staff needs a lot of training and 38\% requires very little training;

- operating hazards: $70 \%$ of the staff requires a lot of training and $30 \%$ requires slight training;

- leak detection technique: around $84 \%$ of the staff requires a lot of training and the rest requires very little training;

- network operations and maintenance: around $84 \%$ of the staff requires a lot of training and the rest requires very little training;

- GT troubleshooting: more than $90 \%$ of the staff requires a lot of training in this aspect;

- GT shutdown procedure: more than $90 \%$ of the staff requires a lot of training in this aspect;

- startup procedure: $50 \%$ of staff requires a lot of training and 50\% requires some training.

Recommendations: The ET recommends an extensive training in operations of gas turbines since the questionnaire analysis revealed that more than $82 \%$ of the staff requires that.

\subsection{Power Plant Maintenance}

The questionnaire reflected the following facts on the subject of power plant maintenance:

- generator maintenance: $90 \%$ of the staff requires a lot of training and the rest requires very little training;

- spare parts requirements preparation: $90 \%$ of the staff requires a lot of training and the rest requires very little training;

- disassembly component inspection and reassembly procedure: $90 \%$ of the staff requires a lot of training and the rest requires no training;

- maintenance safety procedures: $50 \%$ of staff requires a lot of training and 50\% requires some training;

- high voltage testing of power system equipment: $85 \%$ of staff requires a lot of training and the rest requires little training;

- circuit breaker: $95 \%$ of the staff requires a lot of training and the rest requires very little training; 
- workshop on transformer oil: $70 \%$ of the staff requires a lot of training and around $30 \%$ needs very little training;

- distribution transformers: $95 \%$ of the staff requires a lot of training and the rest requires very little training.

Recommendations: The ET recommends an extensive training in power plant maintenance aspects since the questionnaire analysis revealed that more than $90 \%$ of the staff requires that.

\subsection{Control and Protection}

The questionnaire reflected the following facts on the subject of control and protection systems:

- GT protective devices: $65 \%$ of the staff requires a lot of training, 30\% requires very little training and $5 \%$ does not know;

- indicators and logging equipment: $78 \%$ of the staff requires a lot of training, $14 \%$ requires no training and around $8 \%$ does not know.

- computer control systems: $85 \%$ of the staff requires a lot of training, $10 \%$ requires no training and $5 \%$ does not know;

- monitoring devices: $85 \%$ of the staff requires some training and the rest does not need any training;

- systems alarms and their causes: $85 \%$ of the staff requires a lot of training, $10 \%$ very little training and $5 \%$ does not know.

Recommendations: The ET recommends training in control and protection systems aspects since the questionnaire analysis revealed that more than $79 \%$ of the staff requires that.

\subsection{Power Plant Control}

The questionnaire reflected the following facts on the subject of power plant controls:

- generation control: approximately $40 \%$ of the staff requires some training, $20 \%$ little training, 30\% does not need any training and $10 \%$ does not know;

- modes of plant control: $48 \%$ of the staff requires some training, $15 \%$ little training, $25 \%$ requires no training and $12 \%$ does not know;

- control systems (pneumatic, electronic and digital): $50 \%$ of the staff requires training, $15 \%$ little training, $20 \%$ does not need any training and $15 \%$ does not know;

- control of startup and shutdown: $40 \%$ of the staff requires training, $15 \%$ little training, $25 \%$ does not need any training and $20 \%$ does not know.

Recommendations: The ET recommends light training in power plant controls aspects since the questionnaire analysis revealed that around $50 \%$ of the staff requires that.

\subsection{Gas Turbine Support Systems}

The questionnaire reflected the following facts on the subject of

- oil systems-lube oil \& hydraulic: $60 \%$ of the staff requires a lot of training and $40 \%$ does not need any training;

- various auxiliary systems: $50 \%$ of the staff requires a lot of training and $50 \%$ does not need any training;

- environmental control equipment: $30 \%$ of the staff requires training and $70 \%$ does not need any training.

Recommendations: The ET recommends light training in GT support systems aspects since the questionnaire analysis revealed that around $47 \%$ of the staff requires that.

\subsection{Alarm Response \& Hazard Communication}

The questionnaire reflected the following facts on the subject of:

- identify systems equipment in alarm: $90 \%$ of the staff requires a lot of training and $10 \%$ does not need any training;

- hazard communication: $90 \%$ of the staff requires a lot of training and $10 \%$ does not need any training;

- hazard chemicals: $80 \%$ of the staff requires a lot of training and $20 \%$ does not need any training.

Recommendations: The ET recommends an extensive 
training in alarm response and hazard communication aspects since the questionnaire analysis revealed that around $87 \%$ of the staff requires that.

\subsection{Safety in Power Plant}

The questionnaire reflected the following facts on the subject of:

- fire protection: $40 \%$ of the staff requires training and $60 \%$ does not need any training;

- fire aid: $40 \%$ of the staff requires training and $60 \%$ does not need any training;

- safety operation: $45 \%$ of the staff requires training and 55\% does not need any training;

- abnormal operation and record equipment history: $35 \%$ of the staff requires training and $65 \%$ does not need any training.

Recommendations: The ET recommends a light training in safety aspects since the questionnaire analysis revealed that around $41 \%$ of the staff requires.

\section{Conclusions}

The results from the study indicated that, there are five different categories of power plant staff development programs that are anticipated by the respondents in an effort to improve the productivity and efficiency of the power plant. In light of the results, it is recommended that, WAJPCO established power plant staff development plan based on the priorities listed by the respondents, taking into consideration the differences between the various power plant clusters, as a next step we will conduct the TNA based on KPI (key performance indicator).

\section{References}

[1] Dinah, G., Daniel, K., Isabel, W., and Jayne, C. 2004. "Training Needs Analysis. A Literature Review and Reappraisal." International Journal of Nursing Studies 41 (5): 471-86.

[2] Pearson, G. A. 1987. "Business Ethics: Implications for Continuing Education/Staff Development Practice." Journal of Continuing Education in Nursing 18 (1): 20-4.

[3] Boydell, T. H. 1976. The Identification of Training Needs. Portsmouth: British Association for Commercial and Industrial Education, Grosvenor Press.

[4] Walklin, L. 1991. The Assessment of Performance and Competence: A Handbook for Teachers and Trainers. London: Stanley Thornes.

[5] Jeou, S. H., and Lin, L. 2013. "Training Needs Assessment in a Hotel Using 360 Degree Feedback to Develop Competency-Based Training Programs." Journal of Hospitality and Tourism Management 20: 61-7.

[6] Rohana, O., Fauziah, N., Muna, K. S., Zubaidah, Z. A., and Ismie, R. 2011. "Academic Staff Development in Universiti Teknologi MARA-A Perspective Using Training Need Analysis." Presented at the 2011 ISBEIA (IEEE Symposium on Business, Engineering and Industrial Applications), Langkawi, Malaysia.

[7] Zheng, C., Zhanwen, N., and Pengfei, W. 2011. "Operational Skill Training Needs Analysis for Manufacturing Industry." Presented at the 2011 ISBEIA (IEEE Symposium on Business, Engineering and Industrial Applications), Langkawi, Malaysia.

[8] Jianping, H. 2011. "Training Needs Analysis of Talent Intermediary Organization Based on Goldstein Model." Presented at the 2011 ISBEIA (IEEE Symposium on Business, Engineering and Industrial Applications), Langkawi, Malaysia. 